\title{
Circulation in the Mediterranean Sea: evidences, debates and unanswered questions
}

\author{
CLAUDE MILLOT \\ Laboratoire d'Océanographie et de Biogéochimie, Antenne LOB-COM-CNRS, BP 330, \\ F-83507 La Seyne sur Mer, France. E-mail: cmillot@ifremer.fr
}

\begin{abstract}
SUMMARY: The overall counterclockwise alongslope circulation of Atlantic Water (AW) in the western basin of the Mediterranean Sea is now generally accepted. As the eastern basin displays similar general features, why is it generally assumed to function in a different way, and why is AW now said to circulate across the interior of the eastern basin? Relatively huge mesoscale anticyclonic eddies induced by the instability of the AW circulation in the south of the western basin have lifetimes up to several years. It is possible that they extend down to the sea bottom and play a major role in the distribution of all water masses. Why have apparently similar eddies generated in the eastern basin never received specific attention? Once formed, Mediterranean Waters (MWs) must spread and circulate before outflowing. Why have simple dynamical arguments for understanding the circulation of AW, such as the Coriolis effect, rarely been considered for the circulation of MWs? In this paper we address these major aspects of water circulation in the Mediterranean Sea. In order to be as objective and convincing as possible, and to write a paper that can be understood by as broad a readership as possible, we have chosen to present only raw data sets that can be easily interpreted by the reader without any help from the author. Based on the evidence provided by these data sets, we specify the current debates and list what we think are the main unanswered questions.
\end{abstract}

Keywords: Mediterranean Sea, overall circulation, mesoscale, processes.

RESUMEN: CiRCULACión EN El MAR MEDITERRÁNEO: EVIDENCIAS, DEBATES Y PREGUNTAS SIN RESPONDER. - En la cuenca occidental del mar Mediterráneo, la existencia de una circulación global ciclónica del Agua Atlántica (AW) siguiendo el talud continental es actualmente un hecho comunmente aceptado; ya que la cuenca oriental muestra unas características globales similares, ¿por qué en general se supone que funciona de forma distinta?, y ¿por qué se dice que el AW circula por el interior de la cuenca oriental? Remolinos de mesosescala considerablemente grandes, inducidos por la inestabilidad de la circulación del AW en el sur de la cuenca occidental, llegan a permanecer hasta varios años, posiblemente se extienden hasta el fondo, y tienen un papel fundamental en la distribución de todas las masas de agua; ¿por qué remolinos aparentemente similares generados en la cuenca oriental nunca han recibido ninguna atención? Una vez formadas, las distintas Aguas Mediterráneas (MWs) tienen que esparcirse y circular antes de llegar a salir de su cuenca; ¿por qué los argumentos dinámicos simples que permiten entender la circulación del AW, tales como el efecto de Coriolis, han sido muy raramente considerados para explicar la circulación de las MWs? Estos son los aspectos fundamentales de la circulación en el Mar Mediterráneo que analizamos aquí. Para ser lo más objetivos y convincentes posible, y escribir un artículo comprensible para el mayor número de lectores, hemos elegido presentar sólo conjuntos de datos sin procesar que puedan ser fácilmente interpretados por el lector sin ninguna ayuda por parte del autor. En base a las evidencias proporcionadas por estos conjuntos de datos, detallamos los debates actuales y enumeramos las que consideramos principales preguntas sin responder.

Palabras clave: mar Mediterráneo, circulación general, mesoescala, procesos.

\section{INTRODUCTION}

Current debates about Mediterranean Sea circulation and more generally, about how it functions, are a result of history and of the dramatic differences in the research resources of the riparian countries. These debates are also a consequence of differences in sampling strategies and in procedures for analysing the available in situ and satellite data sets. Finally, they are a consequence of the difficulties 
that the scientific community has in considering information it is not familiar with, and of its reticence to reconsider what it has been told, hence to accept new ideas. How did these various causes come about? During most of the last century (up to the 80s), the largest research resources were in the countries and laboratories located in the north of the western basin (Spain, France, Italy) and in the eastern basin (Italy, former Yugoslavia). Therefore, the focus was on the coastal circulation in these countries. Furthermore, most ships had relatively limited capabilities, and satellite information was not yet available. Partly thanks to collaboration with several non-Mediterranean countries, other studies addressed the major processes driving the functioning of the sea (dense water formation) that occur just offshore. Therefore, the Provençal subbasin (off the Gulf of Lions) has been especially well described (e.g. all works from the MEDOC group). In addition, key-places such as the Strait of Gibraltar and the Channel of Sicily have received particular attention. Note that we use specific terms such as sea, basin, subbasin, gulf, strait and channel for rigorousness and clarity.

Studies conducted elsewhere in the sea were not so detailed, and hydrological data were collected both vertically (with bottles and reversing thermometers) and horizontally (since the mesoscale variability could hardly be appreciated) with relatively large sampling intervals. These in situ data sets were analysed according to what we believe are two very different procedures that are still used nowadays. One procedure is purely objective. It consists in merging all available data sets into a database in order to compute mean fields and geostrophic currents, hence resulting in circulation diagrams that rely neither on personal interpretation nor on dynamical argument (e.g. Wüst, 1961; Ovchinnikov, 1966). Partly because data sets and computing facilities are continuously increasing, many colleagues currently follow this kind of statistical procedure because it is fully objective, even though possibly misleading. Its results (whether they are right or wrong!) are generally easily accepted. The other procedure can be considered as subjective. It consists in trying to find, from among all the available data sets, links that are consistent with simple dynamical arguments and elementary computations. For instance, on the basis of a relatively limited set of hydrological data, Nielsen (1912, p.134) depicted the circulation of Atlantic Water (AW; http://www.ciesm.org/events/RT5-
WaterMassAcronyms.pdf) as counterclockwise, "due in the first place to the earth's rotation, which bends the current to the right and thus forces the inflowing AW up against the coast". Amazingly, experts in the objective procedure more or less ignore this subjective argument about the Coriolis effect and topography, and do not deal with it in the results of their own analyses. Note that such a blind objective analysis can lead to imagining that AW can permanently cross a basin or that Mediterranean Waters (MWs) can cross the western basin and flow directly towards Gibraltar (see the section on Circulation of MWs). Experts in the objective procedure generally give little credit to sparse data collected in places not previously sampled, while experts in the subjective procedure generally consider that all available data are reliable and must fit with a general concept. Although I use the subjective procedure I recognise that it is based largely on personal feeling, which might explain why it is generally not easily accepted, and why I have been personally involved in some of the major recent debates about circulation. Without knowing whether I have been right or wrong, I provide below some examples showing how the scientific community finds it difficult to accept new ideas that are roughly opposed to those that they have accepted for decades.

At the end of last century (80s-90s) a series of international programmes were conducted e.g. GIBEX in the Strait of Gibraltar, WMCE and PRIMO in the interior of the western basin. New circulation diagrams were proposed for that basin (Millot, 1987a, 1999), which positively considered the previous ones and refined them by evidencing, in particular, the importance of the mesoscale in the south of the basin. This is now generally recognised and was made possible partly thanks to special links we established with Algeria and the possibility we had to sample the Algerian national waters. In addition, the diagrams we proposed also gave evidence (according to us!) of the role of the Coriolis effect in driving the circulation of all water masses closely alongslope, a feature that has been easily recognised in the western basin for AW but is still debated for MWs (as emphasised by Millot and Taupier-Letage, 2005a). As we strongly believe in the importance of the Coriolis effect and rely on the unbiased information provided by satellites (a bit of experience generally makes interpreting this information possible), we believe that most of our results were obtained mainly because we analyse satellite images individ- 
ually (i.e. not statistically) and use them to locate our samplings in near real time. Consequently, we made a fine sampling (a few $\mathrm{km}$ spacing) of the basin edges, and we collected a significant amount of long-term eulerian current time series (about 100 year point in total, which could represent a significant percentage (some 10s \%) of the current time series available in relation to the sea).

Meanwhile, in the eastern basin, a large number of teams mainly from northern riparian countries (eastern Italy, Greece, Turkey, Israel) worked together for the first time within the international programme POEM that was lead by teams from non-Mediterranean countries. Compared to our own strategy in the western basin, POEM's strategy was markedly different. In situ sampling was mainly performed on regular and relatively large grids (a few 10 s of $\mathrm{km}$ ) mainly in the interior of the basin. Satellite data were used only accessorily and statistically, and Eulerian time series were relatively rare. In addition, only marginal links were established with southern countries. Mainly due to the limited confidence in satellite imagery and in previous works that depicted a counterclockwise circulation around the basin (e.g. Nielsen, 1912; Ovchinnikov, 1966), the POEM group proposed diagrams that avoid considering any kind of feature in the south of the basin and depict currents or jets that cross the basin interior before eventually proceeding clockwise (e.g. Robinson et al., 1991; Robinson and Golnaraghi, 1993; Malanotte-Rizzoli et al., 1997).

Satellite images analysed individually over several years, in particular during the POEM campaigns, have recently lead to a dramatically different circulation diagram for AW that is still consistent with the POEM in situ data sets (Hamad et al., 2004, 2005a,b). This emphasises our conviction that all data sets are initially reliable and that only the analyses of data sets can be doubtful!

In addition to the particular research history of each basin, the different procedures for analysing both in situ and satellite data sets, and the basic feelings that any scientist has (e.g. about the importance of the Coriolis effect), problems in obtaining a coherent description of the circulation come from the fact that few scientists are interested in data analysis at sea scale. As scientists are often generally only interested in one basin or even in one subbasin, they focus more on the differences than on the similarities between the basins and the subbasins. Although there are obvious differences between the western and eastern basins, we think that they also have similarities (and also with the Japan Sea; Millot, 1992). We recently proposed a unified image of the circulation of all water masses (AW and MWs) in the whole Mediterranean Sea (Millot and Taupier-Letage, 2005b). This image satisfies the most basic dynamic arguments (such as the Coriolis effect), and it is consistent with all available data sets (both in situ and remote). The most recent numerical simulations of the circulation (e.g. Alhammoud et al., 2004; see also MERCATOR (http://www.mercator-ocean.fr/) and MFSTEP (http://www.bo.ingv.it/mfstep/) products) clearly support this image (for AW at least).

We present satellite and in situ raw data sets that provide evidence, without involving any computation, of some major circulation features. We also specify the most debated features. Finaly, we specify the major unanswered questions about the functioning of the Mediterranean Sea in general, and the circulation within the Sea in particular. Contrary to what we did in our last papers (Hamad et al. 2004, 2005a,b; Millot and Taupier-Letage, 2005a,b; Millot et al., 2005), we have avoided citing most of the analyses we disagree with. This is obviously not because we have weakened our plain-spoken attitude (which is still increasing ... although asymptotically), or wanted to filter the information (these papers are directly available online), or wanted to cite mainly our own works (we are aware that selfcitation does not help, but the readers sometimes have to be reminded of original works) or influence the reader's opinion (who is advised to just look at the figures and make their own analysis). This is because we hope that, by doing this, some of our colleagues will not feel "aggressed" and will objectively consider information they have yet not wanted to consider!

\section{EVIDENCES AND DEBATES}

\section{Overall circulation of AW}

It is obvious that obtaining an overview of the AW circulation in the whole sea from in situ (hydrological and/or dynamical) data is theoretically possible. However, due to the variations in the characteristics of AW along its course, the seasonal and mesoscale variability of the phenomena and the necessity to take accurate samples, (not only in the interior of the sea i.e. within international waters but also alongslope i.e. within nation- 


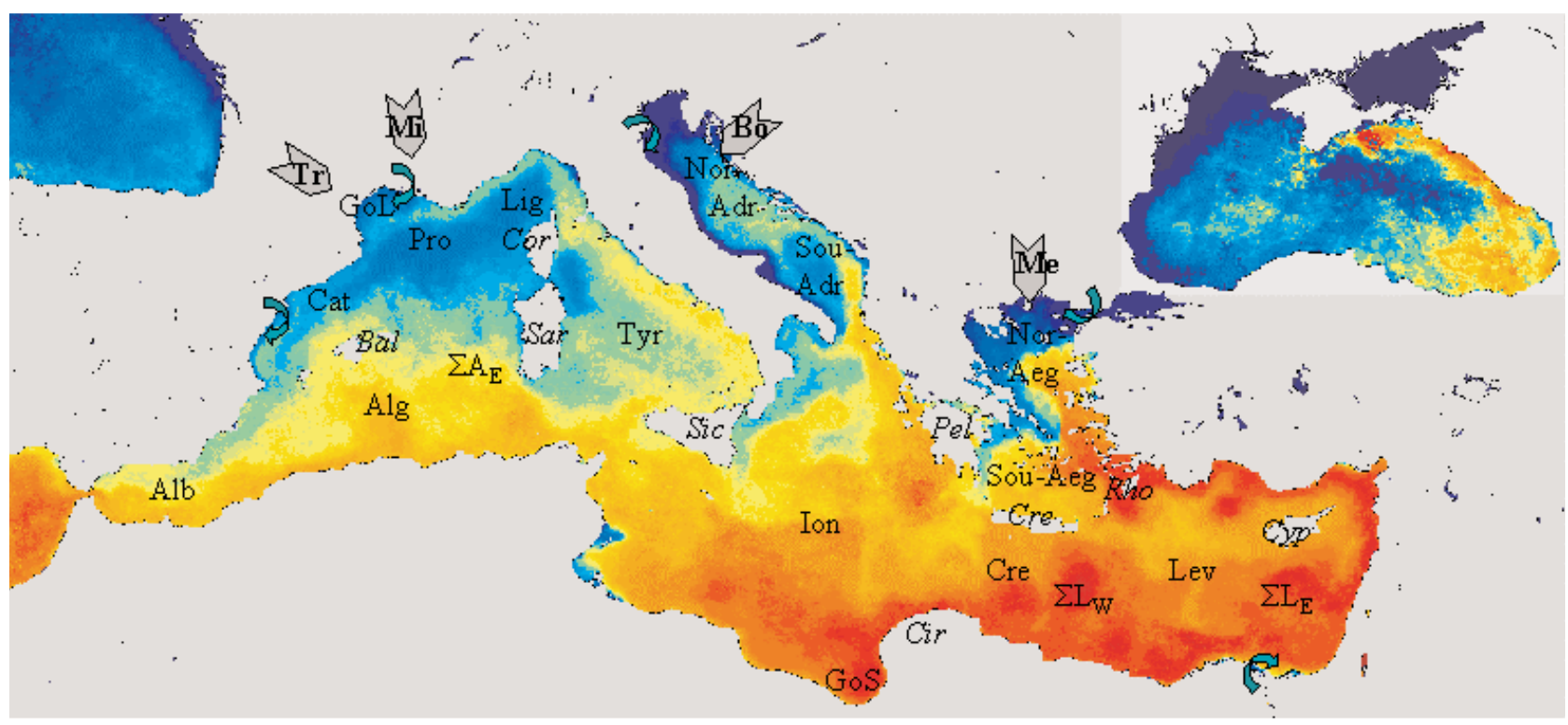

FIG. 1. - SST composite image for January 1998 (the Black Sea has its own colour scale) computed from data get from the DLR ("Deutsches Zentrum für Luft- und Raumfahrt”, http://eoweb.dlr.de). Note that a composite image is not an average one, so that features (absolute values, shape of the isotherms, gradients, etc.) are, from place to place, exactly as measured on a given day (i.e. a few-minute passage) during the considered period. See text for comments and abbreviations (from Millot and Taupier-Letage, 2005b).

al waters of the riparian countries), obtaining an overview would "only" require close collaboration between all the riparian countries and 10 to 20 oceanographic ships able to work everywhere within the sea during weeks if not months! As this is unrealistic, it is easier to analyse readily available (e.g. http://eoweb.dlr.de) satellite information in light of the very basic knowledge that everybody has about the functioning of the sea.

The monthly composite image in Figure 1 was built from all sea surface temperature (SST) values measured at $1 \mathrm{~km} \times 1 \mathrm{~km}$ pixels several times per day in January 1998 by considering only the largest values, this avoids the effects of cloudiness (which lowers the values). January is a convenient month since the zones of dense water formation are relatively cool and the AW entering the basin is warmer than the AW that is resident in that basin (the reverse occurs in summer, and in spring and fall there is an intermediate unclear situation). We believe that this image is representative of the SST values for the winter months, which range from $\sim 18^{\circ} \mathrm{C}$ (red, eastern basin) to $15-16^{\circ} \mathrm{C}$ (orange-yellow near Gibraltar) to $\sim 13^{\circ} \mathrm{C}$ (light blue, dense water formation zones in the Provençal (Pro) and Ligurian (Lig) subbasins) to $\sim 10^{\circ} \mathrm{C}$ or less (dark blue, the river outflows (green arrows) in the Adriatic (Adr), and the Black Sea). We also believe (we computed all monthly composites over several years) that it is representative of all months and years for what concerns most of the general circulation features of the 100-200-m layer of
$\mathrm{AW}$, as these characteristics do not vary seasonally in a significant way for any month or year. This image was then built in a fully objective manner.

Anyone (i.e. not necessarily someone with an oceanographic background!), aware that AW enters continuously near the surface through the Strait of Gibraltar, may notice that AW is first cooled in the Alboran (Alb) due, as we now know, to the strait's dynamics and the intense mixing occurring there. Focusing on the western basin, this person can then see that relatively warm waters are found close (i.e. as a ribbon) along the basin edges, and that they encounter specific variations: AW is identified by SSTs that are rather constant in the Algerian, then decrease from the Tyrrhenian to the Ligurian up to the Provençal before increasing from the Catalan (Cat) up to the Alboran sea. It is easy to imagine that air-sea interactions are especially intense in the north of the basin, with cool and dry air masses transported in winter by the violent Mistral (Mi) and the Tramontane (Tr) winds. Therefore, it is obvious that the overall AW movement propagates counterclockwise alongslope and forms a basin-wide circuit. We call this kind of circuit a "gyre". It is closely linked to the topography, and we prefer using counterclockwise (eventually clockwise) to qualify it. Warm patches in the Algerian are associated with Algerian Eddies (AEs; Millot et al., 1997). An "eddy" is a mesoscale feature that is not linked to the topography, and we prefer using anticyclonic (eventually cyclonic) to qualify it. The AEs are generated by instabilities of 
the gyre in the south, particularly off Algeria (i.e. not off either Morocco or Tunisia due to, we hypothesise, the shallower bathymetry there). Therefore, Millot (1985) proposed naming this part of the gyre the Algerian Current. The northern parts of the gyres have characteristics that are similar in all semienclosed seas or basins. Therefore, Millot (1992) proposed naming them the Northern Current (an adjective specifying the sea or the basin can be added if necessary). Cool patches in the Provençal and the Ligurian subbasins are associated with the zones where WIW (Western Intermediate Water) and WMDW (Western Mediterranean Deep Water) are formed. It is also possible to note the cool zone east of the Strait of Bonifacio where dense water might have formed or occurred in the past (Fuda et al., 2002). Hence, anyone can easily recognise all basic features of the AW circulation in the western basin on a single satellite image, even though these images are not as cloud-free as the composite (i.e. not averaged) image shown in Figure 1!

Keeping in mind the above description, anyone can easily recognise similar features in the eastern basin, with the warmer AW found mainly along the basin's edges, and its temperature displaying continuous variations. SSTs first increase from the Channel of Sicily to the Gulf of Syrta (GoS), due to the marked southward displacement encountered by AW. Then, SSTs are roughly constant from the Ionian (Ion) to the Levantine (Lev) subbasins, since the AW is protected from the most severe airsea interactions, that occur in the Aegean due to the Meltem (Me) and the Adriatic due to the Bora (Bo), which make the SSTs decrease. Finally, SSTs increase again in the Ionian due to a southward displacement along the Italian peninsula and Sicily where AW closes its counterclockwise alongslope gyre around the whole eastern basin. As in the Algerian sea, warm patches in the south of the Ionian and the Levantine give clear evidence of mesoscale eddies. Note that there is also evidence of this counterclockwise alongslope circulation in the Black Sea. Although basic forcings are dramatically different. In the Black Sea very cool, fresh surface waters enter mainly from rivers in the north-western part of the sea before continuing to warm up while circulating around it (a feature now well recognised that was first evidenced by Le Vourch et al., 1992).

This kind of analysis of the surface circulation in the eastern basin is consistent with i) the pioneering work of Nielsen (1912) and his considerations of the
Coriolis effect, ii) the objective analysis of all hydrological data sets (e.g. Ovchinnikov, 1966), iii) the analysis of the first available satellite images (Le Vourch et al., 1992), and iv) the similarities evidenced between the western and eastern basins (Millot, 1992). Therefore, one single image confirms that AW circulates counterclockwise, and specifies that this circulation is continuous and occurs closely alongslope. However, the POEM group (e.g. Robinson et al., 1991; Robinson and Golnaraghi, 1993; Malanotte-Rizzoli et al., 1997), proposes a circulation diagram for AW that depicts major currents (the so-called "Atlantic Ionian Stream" and "Mid Mediterranean Jet") basically crossing the Ionian and the Levantine, and forming branches that flow clockwise in the northeastern Ionian and southeastern Levantine without any clear continuity at basin scale. Obviously, the POEM group did not consider the previous in situ or satellite data analyses, any basic argument, or any single satellite image contemporaneous to their experimental and theoretical works. Therefore, there is a major debate about the overall circulation of AW in the eastern basin.

Millot and Taupier-Letage (2005a) proposed a schematic diagram for the circulation of AW in the whole Mediterranean Sea that is clearly and fully consistent with all available in situ and satellite data sets. They also proposed tentative diagrams for the circulation of the intermediate and deep MWs.

\section{Mesoscale eddies in the south of the basins}

The infrared images of the eastern part of the Algerian subbasin in Figure 2, taken 3-5 months apart, clearly show how large variability is due to mesoscale activity in the zone referred to as $\Sigma \mathrm{A}_{\mathrm{E}}$ in Figure 1. First, note the relatively large diameter (100-200 km up to $\sim 250 \mathrm{~km}$ ), intensity (up to $\sim 1 \mathrm{~m} / \mathrm{s}$ from ship borne ADCP data) and counterclockwise displacement of anticyclonic AEs generated in 96 (96-1), 97 (97-1) and 98 (98-1) by the instability of the Algerian Current. Note that the easternmost warm patch in the Algerian subbasin (Fig. 2) corresponds to both 96-1 and 97-1. We can also see the various transects of hydrological casts (crosses) or towed instruments that were performed appropriately with respect to the AE locations, thanks to receiving satellite information onboard in near real time (Taupier-Letage et al., 2003). In addition, in situ information was continuously provided by the 9mooring array (A) with $\sim 40$ currentmeters that were set in place for one year (Millot and Taupier-Letage, 

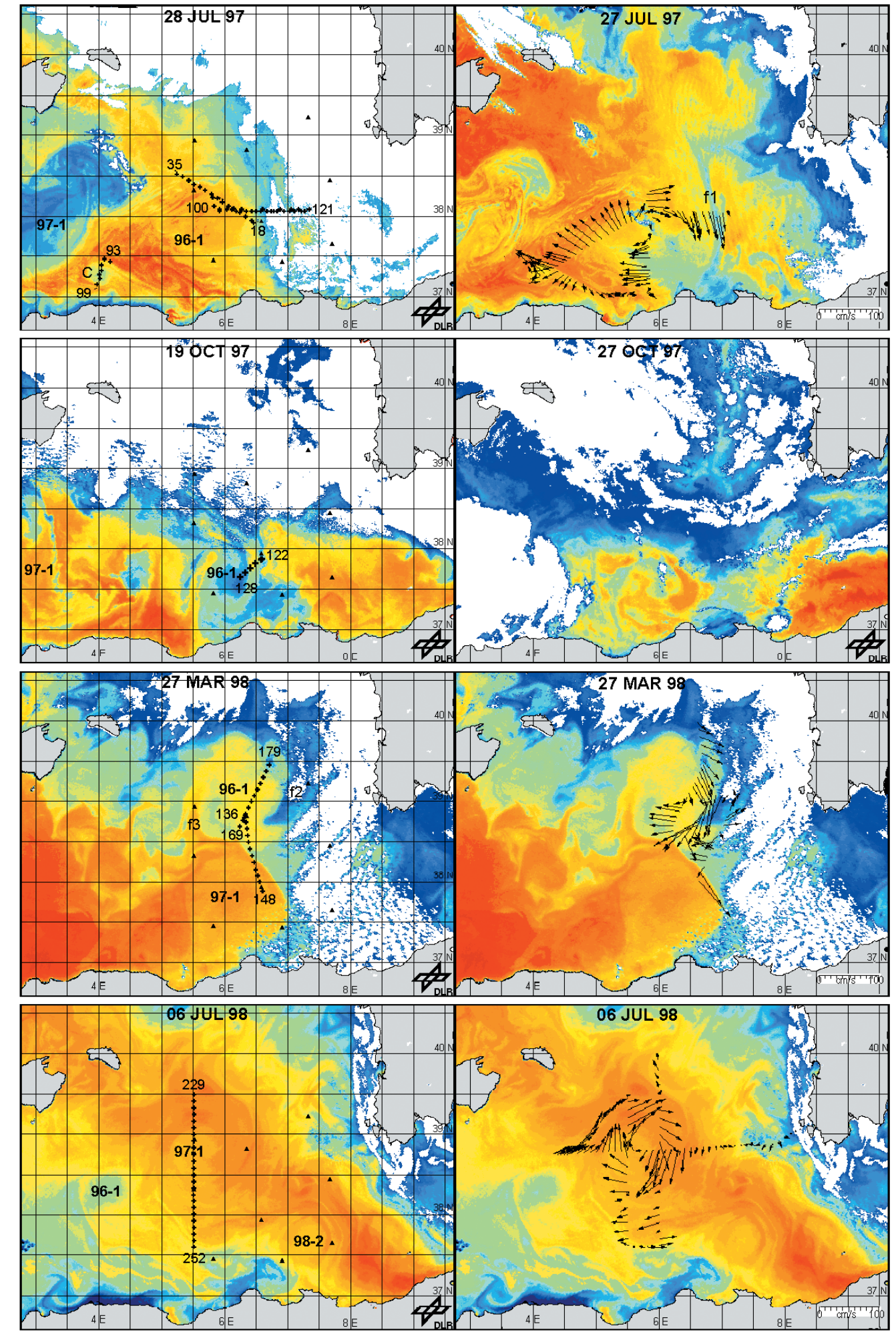

FIG. 2. - Mesoscale situation and sampling during the ELISA cruises (only the best time-coherent subsets of satellite and in situ observations are presented, from Taupier-Letage et al., 2003). +: CTD transects discussed in text, identified by their end-station numbers. $\mathbf{\Delta}$ : Mooring. Temperature on NOAA/AVHRR images increases from blue to red. $\rightarrow$ : Shipboard ADCP currents in the 16-50 m layer. a) ELISA-1 CTD transects over NOAA/AVHRR image of July 28, 1997. b) ADCP currents from July 24 to August 2, 1997, over NOAA/AVHRR image of July 27, 1997. c) ELISA-2 CTD transect over NOAA/AVHRR image of October 27, 1997. d) NOAA/AVHRR image of October 27, 1997 (repeated). e) ELISA-3 CTD transects over NOAA/AVHRR image of March 27, 1998. f) ADCP currents from March 26 to 28, 1998 , over NOAA/AVHRR image of March 27, 1998. g) ELISA-4 CTD transect over NOAA/AVHRR image of July 06, 1998. h) ADCP from July 1 to 6, 1998, over NOAA/AVHRR image of July 6, 1998. 

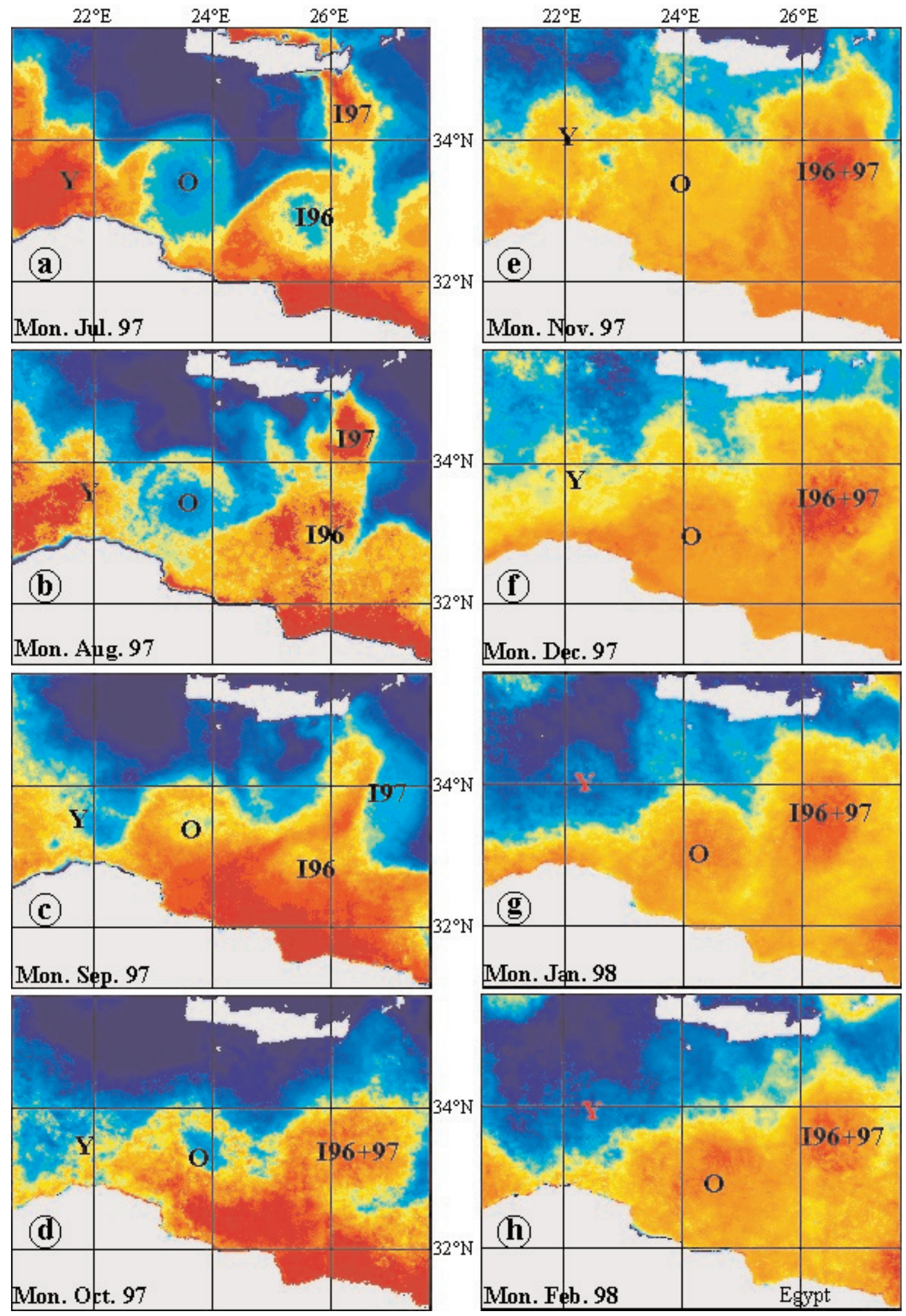

FIG. 3. - The Ierapetra (I96 and I97) and the Libyo-Egyptians (O and Y) mesoscale eddies from July 1997 to February 1998 (from Hamad $e t$ al., 2004, 2005b). 
2005a) and from 20 lagrangian floats that drifted at intermediate depths in the subbasin. AEs, such as 98-1 when it was in the far western Algerian, were also studied with surface drifting buoys that were launched at places chosen from the infrared imagery and that remained trapped by the AEs for a while (Salas et al., 2002; Font et al., 1998, 2004). Thus, we have arrived at quite a good understanding of the mesoscale processes that occurred in the $\Sigma \mathrm{A}_{\mathrm{E}}$ zone, as well as getting some expertise in analysing both satellite and in situ data sets.

Now let us consider (Fig. 3) one of the series of infrared images analysed by Hamad et al. (2004, $2005 \mathrm{a}$,b) in the area that we identify as $\Sigma \mathrm{L}_{\mathrm{w}}$ in Figure 1 , and which corresponds to the area occupied by the "Mersa-Matruh gyre". This gyre is a feature that the POEM group believe to be a more or less permanent anticyclone located south of the so-called "Mid Mediterranean Jet". Figure 3 shows I97, the "Ierapetra anticyclonic eddy" that formed in the summer of 1997 off southeastern Crete (due to interaction between the Meltem wind and the orography), and 196, formed similarly in the summer of 1996. Note that I96 was drifting much closer to Africa during the previous year than it did in July 1997, hence strongly disturbing the eastern gyre there. It is clear that I96 and I97 interact and even merge. Hamad et al. (2004, 2005b), demonstrate that Ierapetra can also propagate westward or remain stationary; in this latter case, it leads to a huge Ierapetra the following year. In the same way, "Pelops" (generated off southern Peloponese) can be recognised more than one year after it is generated, several $100 \mathrm{~s} \mathrm{~km}$ in the interior of the Ionian. Let us say that we believe that an Ierapetra eddy and a Pelops eddy are generated every year, which is far from being generally recognised, and therefore constitutes another debate!

Meanwhile, $\mathrm{O}$ and $\mathrm{Y}$ are anticyclonic eddies that are generated by the instability of the eastern gyre, more specifically of the Libyo-Egyptian Current, as we name the portion of the gyre off eastern Libya and western Egypt. These features are thus the counterparts of the AEs and of the Algerian Current respectively. Note that such large eddies are not generated off Tunisia or the Middle East due to, we hypothesise, the shallower bathymetry there. While $\mathrm{O}$ is slowly propagating alongslope downstream (as usual, these eddies can also remain motionless for weeks/months), Y propagates a bit more rapidly and thus has to drift around $\mathrm{O}$, hence spreading AW toward the basin interior thanks to a paddle-wheel effect (Taupier-Letage and Millot, 1988). The instability of the AW gyre off Libya and Egypt is not debated, since it is not even mentioned by most of the other teams. Even though the series in Figure 3 depicts relatively simple interactions compared to others analysed by Hamad et al. (2004, 2005b), these interactions were not expected from the POEM group's analysis, since this analysis was based mainly (if not only) on in situ data collected far away from Africa. In addition, it is difficult to recognise, on any satellite image, any kind of current or jet continuously meandering across the basin interior. Only by considering in situ and/or satellite data collected north of $33-34^{\circ} \mathrm{N}$ (i.e. avoiding anything that occurs south of $33-34^{\circ} \mathrm{N}$ ), an inexperienced person will possibly imagine a series of arches (the northern parts of the anticyclonic eddies such as I, O and Y) that may be erroneously put in direct continuity to form some kind of "Mid Mediterranean Jet"! Another major debate thus concerns the nature of the mesoscale variability encountered in the south of the eastern basin and its links with the overall circulation, i.e. a cross-basin jet branching into more or less permanent features (the POEM image) vs. an unstable around-basin gyre generating mesoscale eddies that interact with wind-induced eddies generated elsewhere (our own image).

\section{Links between the AW circulation and some zones of MWs formation}

Another feature that is widely debated concerns the circulation around the zones where dense waters (MWs) are formed, sometimes called the "Lions' gyre" and the "Rhodes' gyre". Colleagues using these names conceive these zones to be surrounded by a continuous circuit (we do not use "gyre" which we define differently). This is schematised for instance by the POEM's diagrams, with the "Mid Mediterranean Jet" first surrounding/delimiting the southern edge of the zone where LIW is formed (south of Rhodes island) before continuing counterclockwise all around it as the so-called "Asia Minor Current". Similar diagrams were proposed some decades ago off the Gulf of Lions, when scientists started to study the zone where WIW and WMDW are formed.

However, the image in Figure 1, as well as the images in Figure 3 (the zone where LIW forms can be partially seen in the upper right corner of the images), suggests that both zones are surrounded by two rather different current systems. To the north 
each zone is delimited (not surrounded) by the basin-wide gyre (the Northern Current) that has an alongslope extension that is much larger than the size of the zone itself. To the south each zone is delimited by the northward spreading of AW due to the mesoscale activity that occurs in the south of the basin (in particular in $\Sigma \mathrm{A}_{\mathrm{E}}$ and $\Sigma \mathrm{L}_{\mathrm{W}}$ ). Although surface water in both the north and the south of these zones (still identified as AW) is much less dense (warmer and fresher) than surface water within the zones (that will soon be identified as MW), surface water does not form a continuum around the zones, and AW definitely has characteristics that are relatively different between north and south. Therefore, another debate concerns AW circulation around these two major zones of dense water formation (i.e. a counterclockwise surrounding circuit vs. two rather different current systems).

Maybe surprisingly, the image in Figure 1 clearly indicates that a counterclockwise sub-gyre (see the next paragraph for justification of the term) actually occurs around the zone where the Adriatic Deep Water is formed in the Southern Adriatic (Sou-Adr) subbasin, even though no gyre has been schematised there in recent circulation diagrams (for a review, see Hamad et al., 2005b). Indeed, warm AW enters from the Ionian, proceeds northwards and cools down as it encounters severe air-sea interactions, before turning around the zone and finally coming back into the Ionian. We thus refute the occurrence of a "Lions' gyre" and a "Rhodes' gyre", but claim there is a Southern-Adriatic sub-gyre!

Although we do not want to comment on the reasons that led to the very different views of the links between the basin-wide gyres and the zones of dense water formation, we can propose arguments that can explain the features evidenced by Figure 1. We think that the two major zones where WIW+WMDW and LIW are formed (i.e. off the Gulf of Lions and south of Rhodes island respectively) are characterised not only by the fact that they produce very recognizable waters, but also by the fact that they concern only a portion of the basin and even of the subbasin where they are located. For instance if topography does not constrain the flow strictly to the zone, as happens with the Northern Current, where part of the transported AW sinks and forms MW, then this current has a much larger (i.e. basin) scale. It will mainly follow the continental slope, from far upstream to far downstream of the zone. In the Southern Adriatic however, where the east-west narrowness of the subbasin and the markedly shallower depths in both the north (in the Northern Adriatic) and the south (there is a sill at the Channel of Otranto) form a pit, the topography constrains the flow of AW; then, part of the eastern basin gyre will describe a sub-gyre in the Southern Adriatic. In the Southern Aegean, where the Aegean Deep Water is formed, the circulation is probably in between the former gyres, since the topography of this relatively small subbasin is relatively complex with numerous openings. However, Hamad et al. (2005b) show that there is a clear tendency for an overall counterclockwise circulation of AW (at least in winter). This circulation, with mesoscale eddies propagating downstream north of Crete (all year long), makes the processes in the Southern Aegean more similar to those occurring in its basin-scale counterparts (off the Gulf of Lions and south of Rhodes island) than to those occurring in the Southern Adriatic.

\section{Circulation of MWs}

LIW in the Algerian is an example that represents the debate concerning the circulation of MWs (at intermediate and greater depths), and also illustrates the two different procedures that can be used in data analysis. Let us consider (Fig. 4) all the hydrological data collected in this subbasin during three experiments conducted in 1986-1987 (MEDIPROD-5), June 1990 (MEDIPROD-6) and 1997-1998 (ELISA), and merge this information together. As LIW is characterised by a maximum in salinity and a relative maximum in temperature at intermediate depths, let us retain these maxima for each cast within a depth interval (below $200 \mathrm{~m}$ ) and draw mean isolines for maximum (a) salinity and (b) temperature. This procedure is completely objective and it clearly and naively suggests that LIW flows continuously southwestwards from Sardinia. This is exactly the result Wüst (1961) obtained, then, this idea was interpreted by many authors as "LIW flowing towards Gibraltar".

To our knowledge, questions such as "How can water sense the place to scape from the Sea at such a distance?" or "Can water be sucked over such a large distance?" were never asked before Millot (1987a,b). As we had never believed in this type of analysis, we imagined that LIW flowed alongslope counterclockwise only due to the Coriolis effect, as imagined by Nielsen (1912) for AW, and that the LIW was occasionally trapped and entrained towards the interior of the subbasin by passing AEs. 


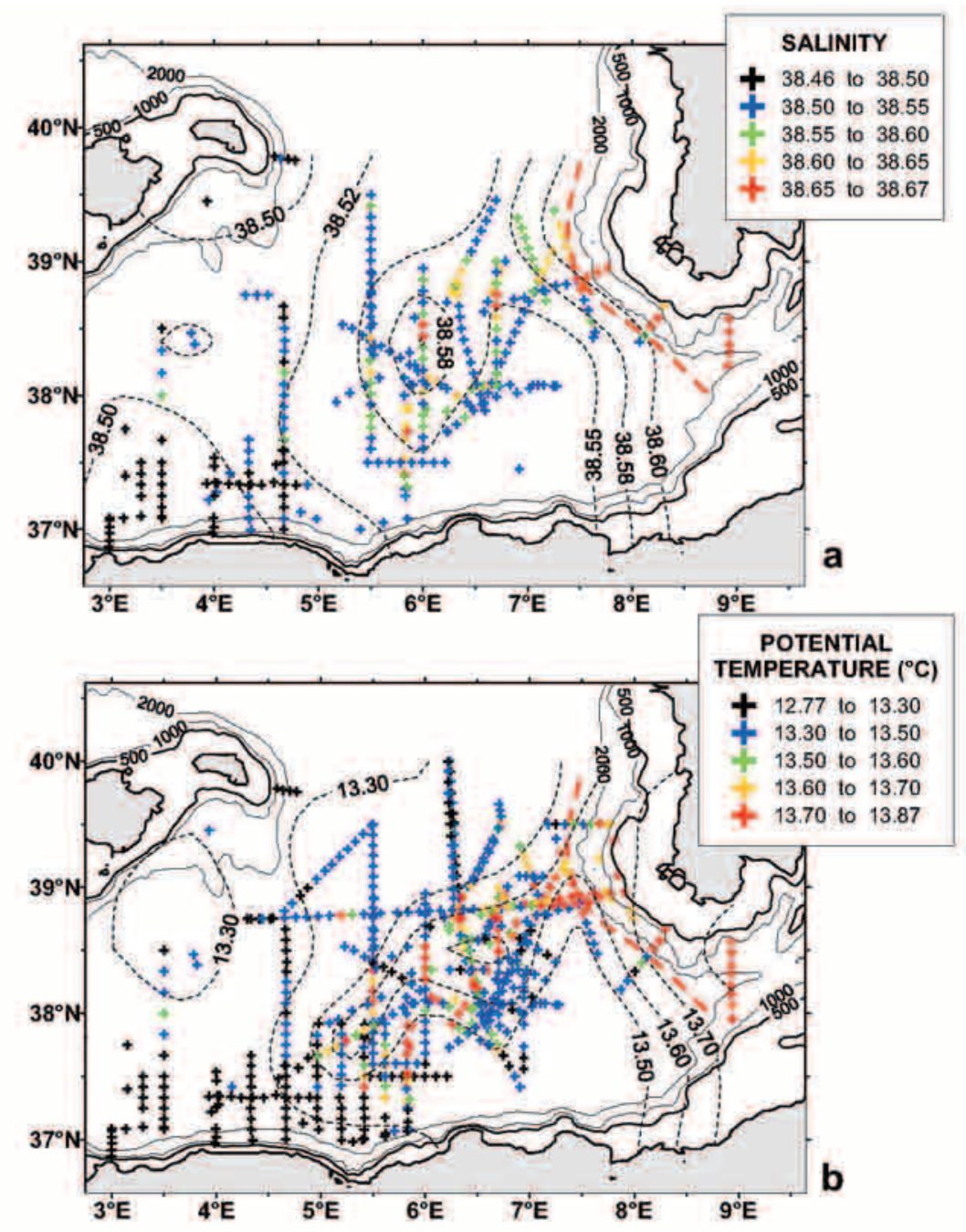

FIG. 4. - Distribution of the salinity (a) and potential temperature (b) maxima associated with LIW from the MEDIPROD-5,6 and ELISA (CTD and XBT casts) in the eastern Algerian subbasin. Associated depths range from $\sim 250$ to $\sim 650 \mathrm{~m}$ for salinity and from $\sim 250$ to $\sim 550 \mathrm{~m}$ for temperature. The dashed black line would result from the unsupervised interpolation of this data set. The dashed red line Figures the LIW vein external edge (from Millot and Taupier-Letage, 2005a).

Even though all the data sets we have obtained from then on support this hypothesis (Benzohra and Millot, 1995a,b; Fuda et al., 2000; Millot and TaupierLetage, 2005a), it is far from being generally accepted. Furthermore, numerical models depicted a socalled "Algerian counter current" of LIW proceeding westwards (i.e. clockwise) along the Algerian slope that reversed in 1986-1987 when we collected current time series there (e.g. Korres et al., 2000; see Millot and Taupier-Letage, 2005a, for a list). Note that no basic argument for this cross-basin or clockwise intermediate current has ever been clearly provided by the modellers themselves, and that in recent models (e.g. Béranger et al., 2004), intermediate waters circulate (in particular off Algeria) alongslope counterclockwise (as proposed by Millot, 1987a,b)!
The circulation of LIW has been debated in other places of the western basin, such as at the outlet of the Channel of Sicily where the indication we provided (Millot 1987a), i.e. circulation firstly alongslope off northern Sicily and then around the Tyrrhenian, was not believed by our colleagues working there, who imagined that LIW proceeded directly to the Channel of Sardinia, hence skipping the Tyrrhenian. Nowadays, these colleagues recognize that LIW actually circulates alongslope counterclockwise around the whole basin, leading the part of LIW that could have missed the exit at Gibraltar to continue eastwards along the whole African slope (as shown by Benzohra and Millot, 1995a) up to the Tyrrhenian again!

The 1-year progressive vector diagrams obtained during the ELISA experiment (Fig. 5) pro- 


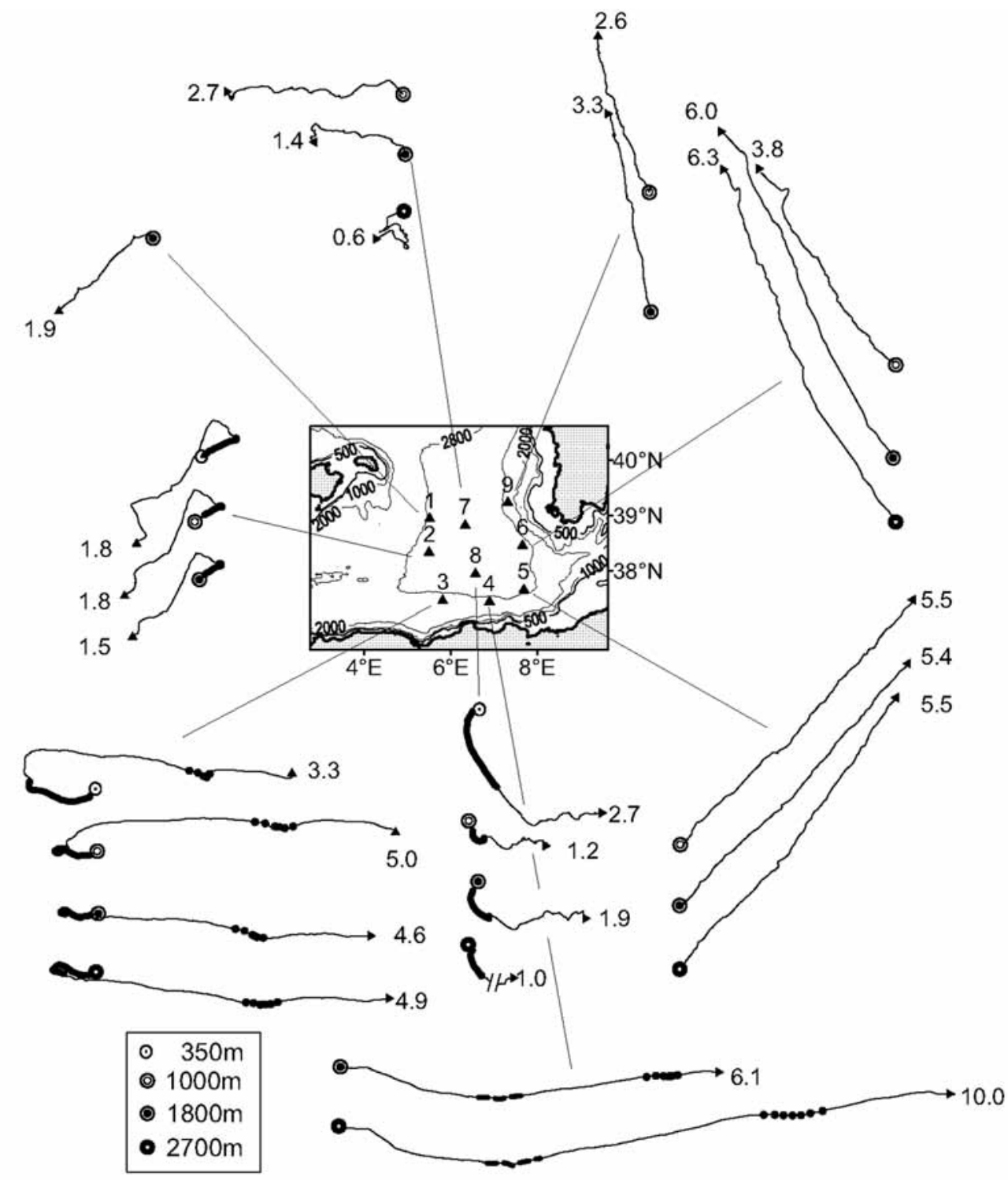

FIG. 5. - One-year progressive vectors diagrams at 350, 1000, 1800 and $2700 \mathrm{~m}$ together with the mean speed in $\mathrm{cm} / \mathrm{s}$; see text for explanations of thickened parts (from Millot and Taupier-Letage, 2005a).

vide another example of the effect of the bathymetry on the circulation of intermediate and deep waters (MWs). As first indicated by Millot (1987a) and illustrated by Millot (1994) waters circulate mainly alongslope counterclockwise and intensities can be relatively large (yearly means of $5-6 \mathrm{~cm} / \mathrm{s}$ up to $10 \mathrm{~cm} / \mathrm{s}$ at $2700 \mathrm{~m}$ ). In the interior of the subbasin, currents are less intense but the topography effect is still obvious. We are not aware of a numerical model that simulates these circulation features that we believe are very important for the functioning of the whole sea, since deep waters must finally outflow from the sea. This is certainly another subject for debate.

\section{Vertical structure of mesoscale eddies}

Images a-b and c-d in Figure 2 show that AE 961 was located over moorings 2, 3 and 8 (see Fig. 5) for several months at the beginning of the 1-year ELISA experiment. Figure 5 shows that the corresponding progressive vector diagrams evidence directions that, at that time (thickened parts), were markedly different from the overall alongslope counterclockwise basin-wide circulation. Currents flowed toward east-northeast at point 2, south-southeast at point 8 and west at point 3 , evidencing anticyclonic currents throughout the whole depth clearly due to the $\mathrm{AE}$ (which was much larger than the overall cir- 
culation itself). We have thus confirmed the hypothesis deduced by analysing the MEDIPROD-5 data set (Millot et al., 1997), and supported by laboratory experiments (Obaton et al., 2000) and hydrological data taken from all depth levels (Ruiz et al., 2002), that AEs are anticyclonic and in phase over the whole depth, with currents as large as several 10s $\mathrm{cm} / \mathrm{s}$ in the 100-200-m layer of AW (see Fig. 2) and several $\mathrm{cm} / \mathrm{s}$ in the whole deep layer (200-3000 m). Since both analytical and numerical models have depicted structures that could result from baroclinic instability (deep cyclones displaying phase shifts over depth were associated with surface anticyclones), the debate was totally unproductive. Nowadays, more sophisticated numerical models support our data analysis and give evidence that AEs can induce anticyclonic motion down to the sea bottom (K. Béranger, pers. com.).

Numerical models now simulate, more or less correctly, a) the formation of such mesoscale eddies within a meander that grows from its parent current (Salas et al., 2002), b) their growth and displacement in the interior of the subbasins and c) their several-year lifetime (up to 3, Puillat et al., 2002). However we still need a dedicated model to understand how the deeper part of the eddy is generated. Because currents in the whole deep layer are similar in both phase and amplitude, while associated with an eddy larger than the surface one. Obaton et al. (2000) hypothesised that within such an eddy the bump of the free surface (several $10 \mathrm{~s} \mathrm{~cm} / \mathrm{s}$ according to satellite altimetry) would not be compensated by a lowering of the interface (between AW and MWs). This would therefore lead to a pressure gradient that could force a barotropic current that was still recognisable in the whole deep layer over a distance equal to the diameter of the surface eddy plus the width of the meander. Considering the effect these mesoscale eddies have on the circulation of all water masses and for all other disciplines (TaupierLetage et al., 2003), there is no doubt that they must be understood and described more accurately than they actually are.

\section{UNANSWERED QUESTIONS}

The particular questions that must be answered in order to better describe the circulation in the Mediterranean Sea have been clearly identified and documented in the section on EVIDENCES AND DEBATES. These questions are: What is the overall circulation of AW and of MWs at the sea/basin scale? What are the links between AW when it circulates and MWs when they start to form and sink? What is the structure of the mesoscale phenomena and their importance in modifying the circulations of the water masses?

However, more general questions and problems also have to be addressed. To describe the circulation as accurately as possible, experimentalists have to objectively analyse all the available data sets in terms of general principles that must be as broad and simple as possible. Then, they can put forward hypotheses that link the data sets with the principles. They can do this and only this! To demonstrate something and finally understand the processes, which is the objective in any scientific domain, experimentalists need equations that can only be handled by modellers since, nowadays, competence in experimentation and in modelling is rarely found in a single person. Therefore, from description to understanding, a community such as the physical oceanographic community studying the Mediterranean Sea has to face a series of problems. Even though it is not easy, we have tried to organise the main thoughts and general questions that come to mind, which were obviously a result of our personal experience: Do we have correct postulates and basic assumptions? What are we presently doing with models and what should be done? What attitude do experimentalists and modellers have with respect to new ideas and what should this attitude be?

\section{Do we have correct postulates and basic assumptions?}

The first set of questions we would like to specify deals with the basic functioning of the sea and the hypotheses often made that some parameters are conserved or that dramatic changes have occurred.

\section{Conservation vs. long-term variations}

For decades and even still today we have been told that transports through the Strait of Gibraltar could be estimated from the conservation of volume and salt content of the sea. While the volume conservation is roughly verified and can even be appreciated correctly, what about the salt content and why should it be conserved? Similarly, reasons for the long-term trends that are observed in the hydrological characteristics of some MWs (e.g. $+0.035^{\circ} \mathrm{C}$ and +0.01 in temperature and salinity per decade for WMDW) 
have been attributed to variations in either the climatic conditions (Béthoux et al., 1990) or the anthropic activity (Rohling and Bryden, 1992), in the sea itself. Why not assume that AW entering at Gibraltar can encounter significant long-term variations too (Millot and Briand, 2002), as evidenced in the ocean (Levitus et al., 2000)? More generally, why not assume that the whole system, i.e. both the ocean and the sea, permanently interact with the atmosphere, so that no hydrological parameter is ever constant? Considering MWs as an example, could it be that a) with short time series (i.e. 1-2 decades) parameters are thought of as constant, b) with time series that are a bit longer (few decades), trends are evidenced that are considered as linear, and c) time series of several decades or centuries long are necessary to specify current variations in most of the frequency domain? It seems to us that this idea is obvious; however, why is it so often forgotten?

\section{Changes vs. misinterpretation}

In the preceding paragraph, we support the idea that the hydrological parameters that characterise each of the MWs (and AW as well) have always displayed long-term variations. Could these variations now (i.e. over decades) lead to dramatic changes in the functioning of the sea or in the circulation of the water masses?

An example of well-known significant changes in the functioning of the sea that have taken place during the last decades is the Eastern Mediterranean Transient (EMT, Roether et al., 1996). This consisted in the Aegean water being denser than Adriatic water in the late 80s-early 90s, which is contrary to what occurred previously and later. Less well-known changes have occurred in MWs outflowing through the Strait of Gibraltar, as evidenced by several-month hydrological time series collected just at the sill in 1994, 1995 and 2003-2004 that are consistent with hydrological casts collected nearby (Millot et al., 2005). We interpret the large warming $\left(\sim 0.3{ }^{\circ} \mathrm{C}\right)$ and salting ( 0.06) of the outflow observed during the last decade (that are much larger than those expected from the WMDW trends) as being due to WMDW (formed in the western basin) being replaced by waters from the eastern basin, which can be considered as a Mediterranean Sea Transient (MST). We also hypothesize that the MST could result from the EMT, and that the MST affects the ocean more dramatically than the EMT itself. Amazingly, most of our colleagues to whom our data set and analysis were pre- sented think that our data set is not reliable, cannot envisage that WMDW could not be clearly identified in the outflow, and believe that we have misinterpreted the data. We imagine the sea functioning as a series of taps, each producing a given MW and being more or less open. In our mind, slight changes in the hydrological characteristic and amount of a given MW results in that MW occupying more or less deep levels and encountering more or less intense mixing within the sea, hence being more or less easily identified in the outflow. Why is this idea so hard for most of our colleagues to conceive of?

What about dramatic changes in the circulation that have resulted at seasonal to decadal scales? For instance, what about the seasonal variation in AW circulation that is said (by some colleagues, at least several years ago!) to reverse from counterclockwise to clockwise in a subbasin such as the Ionian? What about the "Algerian counter current" of LIW said to only occur during specific years? Could it be that the circulation in the Levantine was cross-basin during the POEM campaigns and around the basin during the years we analysed this area with infrared images (as commented by some colleagues!)? In other words, could relatively slight changes in the atmospheric forcings or in the hydrological characteristics and density of the water masses lead to dramatically different solutions in the dynamical equations? We do not believe so and think that these alleged changes in the circulation were due to inadequate in situ sampling and ignorance of unbiased satellite information. Since complementary information during past campaigns can only come from still unexploited information from space, what can be done with colleagues who do not believe in this information? Maybe nothing for the time being! As we are able to interpret all available data sets according to a unique circulation diagram (see Millot and Taupier-Letage, 2005b), we believe that, at least during the last decades, circulation has not undergone dramatic changes at seasonal to decadal scales. Therefore, alleged changes in the circulation result from misinterpretation of insufficient data sets and of inefficient numerical models.

\section{What are we presently doing with models and what should be done?}

Another set of questions deals with understanding the circulation within the sea. That is, identifying the major forcings and specifying the major processes. 


\section{Major vs. minor forcings}

Difficulties in separating the major forcings result from the fact that they all lead to the same kind of counterclockwise circulation (not considering the special case of POEM's strange diagram). Some decades ago, when the focus was mainly on the northern part of the western basin, the identified candidates for forcing were: the thermohaline forcing and its associated dense water formation process, the wind stress and even the freshwater input from rivers. Relatively simple process models dealing with each of these forcings entrained a counterclockwise circulation (i.e. some kind of Northern Current): Dense water tending to sink in an unbounded domain entrains, through geostrophic adjustment, a rim current of surface water around it (hence the idea of the "Lions' gyre" previously mentioned) that will persist for the rest of the year (Crépon et al., 1989; we believe that this process is the dominant one). Northwesterly winds blowing in the northern part of the basin entrain, through the Ekman drift, a surface wind-induced circulation towards the south-west that sucks water from the north-east. Fresh water added along the coast over a sea at rest creates an on-offshore barotropic pressure gradient within the sea, hence an alongslope counterclockwise circulation over the whole depth. Unfortunately, modellers have not been critical enough about their models and only emphasise the similarities and not the differences with the observations. For instance, the wind stress, which is believed (correctly or not?) to be a major forcing, does not explain why the Northern Current is so limited in width (as a ribbon, see Fig. 1) or why the circulation is alongslope counterclockwise over the whole depth (as in Fig. 5). It also doesn't explain how the wind stress, that is so variable in both time and space, could lead to such a relatively permanent circulation. Why hasn't separating the candidates, or at least classifying them, been achieved yet?

\section{GCMs vs. process models}

One reason might be that in recent years, computing facilities have been increasing while products from databases (spatial and temporal averages, interpolated fields, etc.) have been made available, so that modellers have naturally been attracted to elaborating more and more sophisticated general circulation models (GCMs) that can be initiated, forced and validated with convenient data products.
Currently, the objectives of most (not all, fortunately!) modellers are to represent at best the observations, eventually assimilating data to prevent models from diverging. Although this is necessary for operational purposes, it is not appropriate from a scientific point of view. Models must also be built in order to understand the processes, and therefore classify the forcings. In this respect, one major question that we would like to specifically formulate (following our own feelings) is: Does the circulation within the sea and the functioning of that sea depend mainly (if not only) on the actual thermohaline forcing (i.e. taking into account the wind effect on evaporation, mixing, etc., but not necessarily the wind stress)? In other words, could the wind stress forcing (with its actual time and space scales) be thought of as not significantly efficient for driving the circulation at sea or basin scale? Could the actual numerical models be used to separate the candidates, or at least to classify and rate them? Is it so inconceivable to use the now efficient numerical codes with sufficiently small space and time steps to build academic models that allow us to study the processes? Or do we have to forget about the idea of understanding the processes, and concentrate on just being able to simulate what we observe?

\section{What attitude do experimentalists and mod- ellers have to new ideas and what should this attitude be?}

Finally, we would like to report on our experience with the scientific attitude of some experimentalists and modellers with respect to new ideas and original procedures.

\section{Old vs. new ideas}

Describing phenomena, which is generally the first step in a scientific approach, is far from being simple in a geophysical domain. This is because relatively reduced data sets are not analysed in the same way by all experimentalists and because experiments cannot be reproduced. Experiments are always unique and they obviously involve a limited number of participants, therefore a consensus about the analysis is not necessarily reached. For instance, personally, in Figure 1 we see a counterclockwise alongslope AW circulation at the sea/basin scale but some colleagues, in particular the POEM group, believe that the information is not reliable. What can an experimentalist who believes he/she is right do to 
convince a huge group of experimentalists and modellers that they are wrong (as he/she believes)? The answer is not easy. Furthermore, a scientist must first of all have doubts about his/her own convictions. Dealing with basic dynamical arguments is inefficient since they are more or less like postulates, and showing new data sets is not convincing since they can be considered to be unreliable. Maybe one way is to propose a common experiment and agree a priori on the computations that will be done with the data sets and on the objectives that will be addressed. This is what we did about the "Mid Mediterranean Jet", even though our joint proposal was not retained.

It is not easy for a person who has believed for years and years in an idea to accept that this idea is wrong. Especially if this person is a specialist in the place (i.e. knows all data sets and papers dealing with that place) and it is a foreigner (i.e. not a specialist in that place) who presents the new idea. We do not know many authors able to write, as we did: "Contrary to what we previously believed, we now think ...".

\section{Objective vs. subjective procedures}

One example is given by the analysis of the in situ data presented in Figure 4. Another example, which has been mentioned several times herein, is the analysis of satellite information, in particular in the thermal infrared. As some of the first Mediterranean researchers to analyse (in the mid 70s) infrared images both individually and statistically (Millot, 1979), and after some 30 years of experience, we must admit that we have failed to convince most of our colleagues that an individual-subjective procedure is much more informative than a statistical-objective one. As it is possible that problems will occur (due to e.g. solar heating during calm days, or dusty/misty air masses), colleagues prefer diluting these problems through statistics instead of trying to use and develop their feeling, which is very easy (we think!). Indeed, compared to an atmospheric isotherm, a marine isotherm has a much more permanent curvature and location in both time (over hours, days and months) and space (each subbasin is characterised by phenomena with specific features). In this way, even slight gradients in a relatively homogeneous zone can provide valuable information, which is not the case with averaged (not composite) images, or when phenomena are moving. However, the major problem we have always encountered-and continue to encounter-is that unlike computing an averaged image with a robust algorithm and a machine, visual analysis involving feeling and experience does not represent a so-called "technique". The conclusion we come to is that nowadays most referees and editors prefer publishing papers showing maps of the sea surface temperature seasonal variability (which generally does not help a lot in understanding the circulation processes) instead of papers describing, for instance, mesoscale eddies; even though this is a kind of censorship of "field oceanography" compared to "oceanography in the lab". However, we are convinced that following an eddy such as Ierapetra, showing that it can cross a subbasin, it can last for years and eventually it can merge with eddies generated elsewhere, leads to a much better understanding of the dynamical processes that drive the circulation.

\section{Experimentalists and modellers}

As mentioned above, in general it is not possible for a single person to perform both experimental work, i.e. collecting and analysing data sets, and theoretical work, i.e. playing with equations and running models. At a first sight, experimentalists perform a job that receives relatively low consideration. They spend a lot of time, effort and money (according to modellers!) collecting data sets, and they produce a relatively low number of papers in which they can only present their own analyses and eventually put forward some hypotheses. They are never able to demonstrate anything because they need equations and hence modellers to do so. At a first sight too, modellers perform a relatively grateful job. With "just a computer" changing this or that parameter allows them to produce a relatively large number of papers and analyses that cannot be criticised... since they are deduced directly from equations! In addition, some (not all!) modellers tend to believe more in the huge so-called "data files" (even though these are only series of numbers, not data) than in "so-reduced data sets" (even though these are the actual data). We will never forget the very poor consideration given by a modeller to " 24 current time series collected off Algeria during 9 months on 8 moorings" ...only!" (sic). Furthermore, the current measured at intermediate depths was opposed to the simulated one! Even though we have always asked for cooperation with modellers, this demonstrates that some (not all!) of them are (were?) really too arrogant. Maybe using a term 
such as "simulation" instead of "model" (a model being generally an example to follow), and avoiding using a term such as "data" for the results of a simulation, could be first steps towards affording experimental work the appreciation it deserves?

Now, comparing the two jobs with some experience, the experimentalists appear to be much luckier since what they produce is more and more valuable and accumulates, while modellers just produce models that replace each other. In addition, experimentalists "only" have to produce reliable data while modellers have to build models that correctly simulate more and more data (provided they believe in them!), so that their task is more and more difficult.

For good science, experimentalists and modellers have to work together; we just hope that the latter will rely more and more on the former...

\section{ACKNOWLEDGEMENTS}

I sincerely thank J. Font and the Editorial Committee of Scientia Marina for having invited me to contribute to this volume, encouraging the authors to include their personal experience, to criticize freely some recent achievements and to point out the still unanswered questions; I thus have had the opportunity to write a kind of synthesis paper, at just the right time! I have been "lucky" with the two referees and I have sincerely appreciated their constructive comments. Finally I would like to warmly thank I. Taupier-Letage for all that we have done together, as well as all my colleagues and the people who have helped me in collecting and analysing such beautiful data sets about the Mediterranean Sea.

\section{REFERENCES}

Alhammoud B., K. Béranger, L. Mortier and M. Crépon. - 2004. Seasonal and mesoscale variabilities of the Eastern Mediterranean circulation from a High Resolution Numerical Model. Proceedings of the Ankara Conference, October 2002, 344-352.

Benzohra, M. and C. Millot. - 1995a. Characteristics and circulation of the surface and intermediate water masses off Algeria. Deep Sea Res., 42(10): 1803-1830.

Benzohra, M. and C. Millot. - 1995b. Hydrodynamics of an opensea eddy. Deep Sea Res., 42(10): 1831-1847.

Béranger, K., L. Mortier, G.-P. Gasparini, L. Gervasio, M. Astraldi and M. Crépon. - 2004. The dynamic of the Sicily Strait: A comprehensive study from observations and models. Deep Sea Res., 51: 411-440.

Béthoux, J.P., B. Gentili and D. Tailliez. - 1990. Warming trend in the Western Mediterranean Deep Water. Nature, 347: 660-662.

Crépon, M., M. Boukthir, B. Barnier and F. Aikman III. - 1989. Horizontal ocean circulation forced by deep water formation. Part I: An analytical study. J. Phys. Oceanogr., 19: 1781-1792.

Fuda, J.-L., C. Millot, I. Taupier-Letage, U. Send and J.M. Bocog- nano. - 2000. XBT monitoring of a meridian section across the Western Mediterranean Sea. Deep Sea Res., 47: 2191-2218.

Fuda, J.-L., G. Etiope, C. Millot, P. Favali, M. Calcara, G. Smriglio and E. Boschi. - 2002. Warming, salting and origin of the Tyrrhenian Deep Water. Geophys. Res. Letters, 29(18): 1886, doi:10.1029/2001GL014072, 2002.

Font J., C. Millot, J. Salas, A. Julia, and O. Chic. - 1998. The drift of Modified Atlantic Water from the Alboran Sea to the eastern Mediterranean. Sci. Mar., 62(3): 211-216.

Font, J., J. Isern-Fontanet and J. Salas. - 2004. Tracking a big anticyclonic eddy in the western Mediterranean Sea. Sci. Mar. 68(3): 331-342.

Hamad, N., C. Millot and I. Taupier-Letage. - 2004. The surface circulation in the eastern basin of the Mediterranean Sea : new elements. Proceedings of the Ankara Conference, October 2002, 2-9.

Hamad, N., C. Millot and I. Taupier-Letage. - 2005a. A new hypothesis for the surface circulation in the eastern basin of the Mediterranean Sea. Prog. Oceanogr. (in press).

Hamad, N., C. Millot and I. Taupier-Letage. -2005 b. The surface circulation in the eastern basin of the Mediterranean Sea as inferred from infrared images. Sci. Mar. (in press).

Korres, G., N. Pinardi and A. Lascaratos. - 2000. The ocean response to low-frequency interannual atmospheric variability in the Mediterranean Sea. Part I: sensitivity experiments and energy analysis. J. Climate, 13 (4): 705-731.

Levitus, S., J.I. Antonov, T.P. Boyer and C. Stephens. - 2000. Warming of the World Ocean. Science, 287 (5461): 2225-2229.

Le Vourch, J., C. Millot, N. Castagné, P. Le Borgne and J.P. Olry. - 1992. Atlas of Thermal Fronts of the Mediterranean Sea Derived From Satellite Imagery. Mém. Inst. Océanogr. Monaco, 16: 1-146.

Malanotte-Rizzoli, P., B.B. Manca, M. Ribera d'Alcala, A. Theocharis, A. Bergamasco, D. Bregant, G. Budillon, G. Civitarese, D. Georgopoulos, A. Michelato, E. Sansone, P. Scarazzato and E. Souvermezoglou. - 1997. A synthesis of the Ionian Sea hydrography, circulation and water mass pathways during POEM-Phase I. Prog. Oceanogr., 39: 153 -204.

Millot, C. - 1979. Wind induced upwellings in the Gulf of Lions. Oceanol. Acta, 2 (3): 261-274.

Millot, C. - 1985. Some features of the Algerian Current. J. Geophys. Res., 90 (C4): 7169-7176.

Millot, C. - 1987a. Circulation in the Western Mediterranean. Oceanol. Acta, 10 (2): 143-149.

Millot, C. $-1987 \mathrm{~b}$. The circulation of the Levantine Intermediate Water in the Algerian Basin. J. Geophys. Res., 92 (C8): 8265-8276.

Millot, C. - 1991. Mesoscale and seasonal variabilities of the circulation in the western Mediterranean. Dyn. Atm. Oceans, 15: 179-214.

Millot, C. - 1992. Are there major differences between the largest Mediterranean seas? A preliminary investigation. Bull. Inst. Océanogr. Monaco, 11: 3-25.

Millot, C. - 1994. Models and data: a synergetic approach in the western Mediterranean Sea. Erice School Proceedings, In: P. Malanotte-Rizzoli and A.R. Robinson (eds.), Ocean Processes in Climate Dynamics: Global and Mediterranean Examples, pp. 407-425. Dordrecht/Boston/London.

Millot, C. - 1999. Circulation in the Western Mediterranean sea. $J$. Mar. Sys., 20: 1-4, 423-442.

Millot, C., I. Taupier-Letage and M. Benzohra. - 1997. Circulation off Algeria inferred from the Médiprod-5 current meters. DeepSea Res., 44 (9-10): 1467-1495.

Millot, C. and F. Briand. - 2002. Tracking long term hydrological change in the Mediterranean Sea Executive summary. CIESM Workshop Series, 16: 7-14.

Millot, C. and I. Taupier-Letage. - 2005a. Additional evidence of LIW entrainment across the Algerian Basin by mesoscale eddies and not by a permanent westward-flowing vein. Prog. Oceanogr., (in press).

Millot C. and I. Taupier-Letage. - 2005b. Circulation in the Mediterranean Sea. Handbook of Environmental Chemistry. , Vol. 1 (The Natural Environment and the Biological Cycles), A. Saliot Ed., Springer-Verlag GbmH and Co. , Heidelberg, in press, http://www.ifremer.fr/lobtln/.

Millot C., J.-L. Fuda, J. Candela and Y. Tber. - (Submitted). Large warming and salting of the Mediterranean outflow due to shifts in dense water formation zones within the sea. Submitted to Geophys. Res. Letters. 
Nielsen, J.N. - 1912. Hydrography of the Mediterranean and adjacent waters. Rep. Dan. Oceanogr. Exp. Medit., 1: 77-192.

Obaton, D., C. Millot, G. Chabert D'Hières and I. Taupier-Letage. -2000 . The Algerian Current: comparisons between in situ and laboratory measurements. Deep-Sea Res. I, 47: 2159-2190.

Ovchinnikov, I., Y. Popov and I. Gertman. - 1990. Investigation of the formation of deep waters in the eastern Mediterranean sea during the $36^{\text {th }}$ cruise of the R/V Ya. Oceanology, 30 (6): 769-771.

Puillat, I., I. Taupier-Letage and C. Millot. - 2002. Algerian eddies lifetimes can near 3 years. J. Mar. Sys., 31 (4): 245-259.

Robinson, A.R., M. Golnaraghi, W.G. Leslie, A. Artegiani, A. Hecht, E. Lazzoni, A. Michelato, E. Sansone, A. Theocharis and Ü. Ünlüata. - 1991. The Eastern Mediterranean general circulation : features, structure and variability. Dyn. Atm. Oceans, 15: 215-240.

Robinson, A.R. and M. Golnaraghi. - 1993. Circulation and dynamics of the Eastern Mediterranean Sea; quasi-synoptic data-driven simulations. Deep Sea Res., 40 (6): 1207-1246.

Roether W., B. Manca, B. Klein, D. Bregant, D. Georgopoulos, V. Beitzel., V. Kovacevic and A. Lucchetta. - 1996. Recent changes in Eastern Mediterranean Deep Waters. Science, 271: 333-335.

Rohling, E.J. and H. Bryden. - 1992. Man-induced salinity and temperature increases in Mediterranean Deep Water. J. Geophys. Res., 97: 11191-11198.

Ruiz, S., J. Font, M.Emelianov, J. Isern-Fontanet, C. Millot and I. Taupier-Letage. - 2002. Deep structure of an open sea eddy in the Algerian Basin. J. Mar. Sys., 33-34: 179-195.

Salas, J., C. Millot, J. Font and E. García-Ladona. - 2002. Analysis of mesoscale phenomena in the Algerian Basin observed with drifting buoys and infrared images. Deep-Sea Res., 49 (2): 245-266.

Taupier-Letage, I. and C. Millot. - 1988. Surface circulation in the Algerian Basin during 1984. Oceanol. Acta, sp. n 9: 119-131.

Taupier-Letage, I., I. Puillat, P. Raimbault and C. Millot. - 2003. Biological response to mesoscale eddies in the Algerian Basin. J. Geophys. Res., 108 (C8): 3245. doi:10.1029/1999JC000117, 2003.

Wüst, G. - 1961. On the vertical circulation of the Mediterranean Sea. J. Geophys. Res., 66: 3261-3271. 
